This is the peer reviewed version of the following article:

Ćurčić Ž., Stepanović J., Zübert C., Taški-Ajduković K., Kosovac A., Rekanović E., Kube M., Duduk B. Rubbery taproot disease of sugar beet in Serbia associated with 'Candidatus phytoplasma solani'. Plant Disease 2021, 105 (2), 255 - 263. https://doi.org/10.1094/PDIS-07-20-1602-RE.

\title{
(c) $(1)(\Theta$
}

This work is licensed under

Creative Commons - Attribution-Noncommercial-NoDerivative Works 4.0 International 
1 Rubbery Taproot Disease of Sugar Beet in Serbia Associated with 'Candidatus Phytoplasma

2 solani'

4 Živko Ćurčića , Jelena Stepanovićb ${ }^{b}$, Christina Zuebert ${ }^{c}$, Ksenija Taški-Ajdukovića ${ }^{a}$, Andrea

5 Kosovac $^{\mathrm{b}}$, Emil Rekanovićb, Michael Kube ${ }^{\mathrm{c}}$ and Bojan Duduk ${ }^{\mathrm{b}}$

6

$7 \quad$ a Institute of Field and Vegetable Crops, Novi Sad 21000, Serbia

$8 \quad \mathrm{~b}$ Institute of Pesticides and Environmental Protection, Belgrade 11080, Serbia

9 c University of Hohenheim, Integrative Infection Biology Crops-Livestock, Stuttgart 70599,

10 Germany

13 Corresponding author: Bojan Duduk; email: bojan.duduk@pesting.org.rs

15 Keywords: Stolbur, Beta vulgaris, Etiology

18 Funding: Ministry of Education and Science, Republic of Serbia

19 451-03-68/2020-14/200214 and 451-03-68/2020-14/200032 


\section{ABSTRACT}

22 Ćurčić, Ž., Stepanović, J., Zuebert, C., Taški-Ajduković, K., Kosovac, A., Rekanović, E., Kube,

23 M., and Duduk, B. 2020. Rubbery Taproot Disease of Sugar Beet in Serbia Associated with

24 'Candidatus Phytoplasma solani'. Plant Disease 104:xxx-xxx.

25 Rubbery taproot disease (RTD) of sugar beet was observed in Serbia for the first time in the 26 1960s. The disease was already described in neighbouring Bulgaria and Romania at the time, but 27 it was associated with abiotic factors. In this study on RTD of sugar beet in its main growing area 28 of Serbia, we provide evidence of the association between 'Ca. P. solani' (stolbur phytoplasma) 29 infection and the occurrence of typical RTD symptomatology. 'Ca. P. solani' was identified by 30 PCR and the sequence analyses of $16 \mathrm{~S} r R N A$, tuf, secY and stamp genes. In contrast, the 31 causative agent of the syndrome "basses richesses" of sugar beet, namely, 'Ca. A. 32 phytopathogenicus', was not detected. Sequence analysis of the stolbur strain's tuf gene 33 confirmed a previously reported and a new, distinct tuf stolbur genotype (named 'tuf d') that is 34 prevalent in sugar beet. The sequence signature of the tuf gene, as well as the one of stamp both correlate with the epidemiological cycle and reservoir plant host. This study provides knowledge 36 that enables for the first time the differentiation of stolbur strains associated with RTD of sugar 37 beet from closely related strains, thereby providing necessary information for further 38 epidemiological work seeking to identify insect vectors and reservoir plant hosts. The results of 39 this study indicate that there are differences in hybrid susceptibility. Clarifying the etiology of 40 RTD as a long-known and economically important disease is certainly the first step towards 41 disease management in Serbia and neighboring countries.

43 Keywords: Stolbur, Beta vulgaris, Etiology 
Rubbery taproot disease (RTD) of sugar beet (Beta vulgaris) was observed in Serbia for the

47 first time in the Central Banat and Northern Bačka regions in the 1960s (Marić 1974; Marić et al. 1970). The disease was already known at the time in neighboring Bulgaria and Romania, but it was associated with abiotic factors (Christova 1950; Marić 1974; Racovita 1959). After its epidemic phase during the late 1960s, the disease abated but remained present in the 1970s, when

51 it was sporadically observed across the region, showing higher prevalence in dry seasons (Marić 52 1974). In 2018, the disease entered a new epidemic phase in Serbia, suggesting that it may be 53 related to current outbreaks in other European sugar beet-growing regions. A condition known in 54 sugar beet crops as low sugar content disease, and also as the syndrome "basses richesses" 55 (SBR), has been reported in France repeatedly since the 1990s, while it has been observed in 56 Germany and Switzerland since 2009 and 2017, respectively (Fankhauser 2019; Richard-Molard 57 et al. 1995; Schröder et al. 2012). The SBR is associated with a phloem-limited prokaryote, 'Candidatus Arsenophonus phytopathogenicus', whose vector is Pentastiridius leporinus 59 (Auchenorrhyncha: Cixiidae) (Bressan et al. 2008, 2009, 2012; Gatineau et al. 2002; Sémétey et al. 2007b). However, another phloem-limited prokaryote, 'Candidatus Phytoplasma solani'

61 (stolbur phytoplasma), is vectored on sugar beet by the same insect, and it has been sporadically 62 detected in SBR-affected plants, albeit it does not play a significant role in SBR etiology 63 (Bressan et al. 2008; Gatineau et al. 2001; Sémétey et al. 2007b). The most apparent symptoms of 64 SBR are the brownish discoloration of taproot vascular tissue, and the deformation and 65 discoloration of young and old leaves. The disease causes a reduction in taproot sugar content as 66 well as losses as high as those exceeding 50\% in France in 1991 (Richard-Molard et al. 1995). In 
67 South America, a sugar beet disease known as "yellow wilt" was observed for the first time in

68 Argentina in the 1930s and later in Chile in the 1940s (Bennett and Munck 1946; Vallejo 1970).

Eventually, it was associated with a phytoplasma belonging to the ribosomal group 16SrIII-J

70 (Castro et al. 2000; Fiore et al. 2015). Yet another disease of unknown etiology with similar 71 symptoms was reported in Arizona, USA (Ruppel 1969).

72 Presence of the SBR agent 'Ca. A. phytopathogenicus' has never been recorded in Serbia, 73 while stolbur as a disease of pepper and other Solanaceae, had been known in Serbia since 1949 74 (Martinović and Bjegović, 1950). The research on the epidemiology of stolbur induced pepper 75 yellow wilt in Serbia, conducted as early as in the 60 s, has confirmed the data on Convolvulus 76 arvensis as the stolbur inoculum source and planthopper Hyalesthes obsoletus 77 (Auchenorrhyncha: Cixiidae) as its vector, corresponding to the previous findings in the former 78 USSR (Aleksić et al. 1967; Suhov and Vovk 1949). Although recent researches of stolbur 79 diseases in Serbia have become mainly oriented toward Bois noir of the grapevine and corn 80 reddening disease (Cvrković et al. 2014; Duduk et al. 2004; Duduk and Bertaccini 2006; Jović et al. 2009; Mori et al. 2013; Kosovac et al. 2019), numerous other annual and perennial crops have 82 also been reported as infected and economically affected by ' $\mathrm{Ca}$. P. solani' such as potato, carrot, 83 parsley etc. (Mitrović et al. 2013, Mitrović et al. 2016).

84 Molecular characterisation of the ' $\mathrm{Ca}$. P. solani' strains can give an insight into the pathogen's 85 epidemiological cycle that permeates natural and cultivated vegetation. Conserved house-keeping 86 tuf gene has been so far demonstrated as the epidemiologically most informative genetic marker 87 indicating the inoculum source plant (Aryan et al. 2014; Atanasova et al. 2015; Kosovac et al. 2016; Langer and Maixner 2004). Another house-keeping gene, $\sec Y$ has also been frequently 89 used in epidemiological studies, while more elaborate tracking of the ' $\mathrm{Ca}$. P. solani' pathways is 
90 feasible when combined with more divergent stamp gene. Variability of the stamp gene follows a

91 specific tuf epidemiological cycle and in some disease outbreaks correlates with specific

92 transmission pathway and vector population (Fabre et al. 2011b; Kosovac et al. 2016; Murolo and

93 Romanazzi 2015).

94 Sugar beet RTD symptoms in Serbia resemble those of sugar beet yellow wilt in South 95 America (leaf yellowing and wilting), more than the SBR in Europe, while the disease pattern (its 96 recurrent epidemic outbreaks and distinctive development, i.e. temporal and spatial distribution), 97 to some extent, is similar to other phytoplasma-induced diseases of annual crops in Serbia 98 (Duduk and Bertaccini 2006). This resemblance indicates a possible association of the disease 99 with phytoplasmas, even though 16 SrIII-J phytoplasmas are not present in Europe and the ' $\mathrm{Ca}$. P. 100 solani' found in France was not associated with symptoms similar to those of the RTD.

101 The latest outbreak of this important disease, alongside its economic impact on sugar beet in 102 Serbia, has enabled trials to be carried out in naturally infected experimental fields, aiming to: (i) 103 clarify the etiology of sugar beet rubbery taproot disease in the main sugar beet growing area in 104 Serbia, (ii) molecularly characterise the causal organism and (iii) evaluate the disease prevalence. 105

\section{MATERIAL AND METHODS}

The etiology of RTD, as well as hybrid sensitivity and disease prevalence, was examined in a long-term stationary trial based at Rimski Šančevi (N 4520'; E 1951') at the Institute of Field and Vegetable Crops, Novi Sad. The location is situated in South Bačka district, the Region of Vojvodina, claiming $27 \%$ and $97 \%$, of total 50,000 ha sugar beet-growing area in Serbia (for the 112 district and the region, respectively). Disease prevalence and hybrid sensitivity were assessed in 2018 and 2019, while the etiology of the disease was examined in 2019. The long-term stationary 
114 trial was set up in 1965 as a four-field crop rotation scheme for sugar beet, corn, sunflower and wheat. The soil type in the field is chernozem, subtype on loess, variety carbonate, form medium deep.

117 Experimental design and data analysis. The experiment was organised in a randomised complete block design observing eight hybrids in 80 replications. The hybrids used in the experiment in 2018 were Tesla, Eduarda, Original, Tajfun, Nansen, Terranova, Nora and Leopolda, while in 2019 the latter two were replaced with Sioux and Sixtus. The hybrids used in

121 the experiment, are widely grown sugar beet hybrids in Serbia. Each sugar beet hybrid was 122 considered a plot treatment. The experimental plot size was $24 \mathrm{~m}^{2}$ (four $12 \mathrm{~m}$ long rows), and 123 wheat was the preceding crop. Field size was 2 ha. Sowing was performed on April 11, 2018 and 124 March 22, 2019, at $0.09 \mathrm{~m}$ distance within rows and $0.5 \mathrm{~m}$ between rows. After the second pair of 125 leaves developed, seedlings were thinned to a final, recommended crop density of 100,000 plants $126 \mathrm{ha}^{-1}$. Standard agricultural practice for sugar beet crops, including herbicides and fungicides, were 127 applied during the vegetation period. Beside insecticide (containing two active ingredients 128 thiamethoxam and tefluthrin) that was used for the seed pretreatment in both 2018 and 2019, the 129 treatments in 2018 included an additional insecticide (containing two active ingredients 130 chlorpyrifos and cypermethrin) foliar treatment against beet weevil on May 4.

131 In October of both years, the prevalence of sugar beets expressing RTD symptoms was 132 determined within each sampling plot by subjecting all samples to symptom observation and 133 counting. The prevalence was calculated using the following formula: prevalence $(\%)=$ number 134 of plants with RTD symptoms/total number of plants x100.

135 One-way ANOVA (analysis of variance) was performed to analyse the collected data 136 separately for each year, using the Statistica 13 software package (2013, StatSoft, Tulsa, OK, 
137 USA) and Tukey's range test for detecting of statistically significant differences between sugar 138 beet hybrids. Only the six hybrids which were used in both years of the experiment were included 139 in the statistical analyses.

140 Symptom observation and sample collection. The experimental production field served for 141 monitoring the occurrence and development of disease and sampling for etiological research.

142 Field observation included monitoring symptoms on leaves and roots at weekly intervals over the 143 vegetation period, starting from 1 May and running until harvest in November.

144 At harvest during the first half of November 2019, 30 symptomatic and 20 asymptomatic samples 145 of the Original sugar beet hybrid were randomly collected from the experimental field for 146 etiological research. Simultaneously, 30 symptomatic and 20 asymptomatic samples of the other 147 seven hybrids tested in the experiment were randomly collected and also subjected to etiological 148 research.

149 Two sugar beet plants with typical symptoms of SBR (HN1220/5 and HN1220/6) were 150 collected from an area with natural SBR infection in Biberach bei Heilbronn, Germany, and they 151 served as SBR positive controls for ' $\mathrm{C} a$. A. phytopathogenicus'.

152 Additionally, three symptomatic and one asymptomatic samples of sugar beet were collected 153 from a commercial field at Bačko Dobro Polje $40 \mathrm{~km}$ north-east of the experimental field (N $154 \quad 45^{\circ} 30^{\prime} 49^{\prime \prime}$; E 1942'59"), another area with natural RTD infection.

155 Molecular detection. Nucleic acid extraction from sugar beet samples was performed from $1560.5 \mathrm{~g}$ of taproot or leaf midrib tissues, following the CTAB protocol (Doyle and Doyle 1990). 157 Total nucleic acids were precipitated with isopropanol, re-suspended in a TE buffer (10 mM Tris $158 \mathrm{pH} 8$ and $1 \mathrm{mM}$ EDTA) and stored at $-20^{\circ} \mathrm{C}$. 
For phytoplasma assessment in the collected samples, direct PCR assays with the universal phytoplasma primer pair P1/P7 (Deng and Hiruki 1991; Schneider et al. 1995), and nested PCR with the primer pair R16F2n/R2 (Lee et al. 1995), were carried out. Each $25 \mu \mathrm{L}$ PCR mix contained 20 ng of template DNA, 1× PCR Master Mix (Thermo Scientific, Vilnius, Lithuania) and $0.4 \mu \mathrm{M}$ of each primer. Samples lacking DNA were employed as negative controls. In total, 1 $\mu \mathrm{L}$ of direct PCR amplicon diluted $30 \times$ in sterile water was used as a template for the nested PCR. Thirty-five PCR cycles were performed, for both amplifications, under previously described conditions (Deng and Hiruki 1991). Six microliters of PCR products were separated in $1 \%$ agarose gel, stained with ethidium bromide and visualized with a UV transilluminator. The detected phytoplasmas were identified by RFLP analysis, using the TrulI (Thermo Scientific, Vilnius, Lithuania) restriction enzyme on $\mathrm{R} 16 \mathrm{~F} 2 \mathrm{n} / \mathrm{R} 2$ amplicons. Restriction products were separated in $8 \%$ polyacrylamide gel, stained and visualized as described above. The P1/P7 PCR products of 12 randomly selected samples were sequenced in both directions, with primers applied for amplification (Macrogen Inc., Seoul, Korea). The obtained sequences were assembled using Pregap4 from the Staden Package (Staden et al. 2000), manually inspected and compared.

174 A 1,688 nt-long nucleotide sequence of the almost complete $16 \mathrm{~S}$ ribosomal RNA gene, the internal spacer region and a 5' portion of the $23 \mathrm{~S}$ ribosomal RNA gene of ' $\mathrm{Ca}$. P. solani' strain 429/19, was deposited in GenBank under accession number MT157232. For identification purposes, the sequence was compared with sequences available in NCBI's GenBank database.

178 For the ' $\mathrm{Ca}$. A. phytopathogenicus' assessment, two separate PCRs were applied to all sugar 179 beet samples analysed in this work. The first one employed the Alb1/Oliv1 primer pair specific to the internal transcriber spacer (ITS) region between the $16 \mathrm{~S}$ and $23 \mathrm{~S}$ ribosomal genes of ' $\mathrm{Ca}$. A. phytopathogenicus', while the other one used the Fra5/Fra4 primer pair, which allows for the 
amplification of the 16S rRNA gene of ' $\mathrm{Ca}$. A. phytopathogenicus'. The conditions for amplification and reaction mix compositions were the same as described previously (Sémétey et al. 2007a; Zreik et al. 1998). The PCR products in both analyses were visualised as described above. The Fra5/Fra4 PCR products of the two SBR sugar beet samples from Germany were sequenced in both directions with primers applied for amplification. The obtained sequences were assembled, manually inspected and compared as described above. A 515 nt-long nucleotide sequence of the 16S ribosomal RNA gene of 'Ca. A. phytopathogenicus' strain HN1220/5 was deposited in GenBank under accession number MT139648. The sequence was compared with available sequences as described above.

Multi locus sequence typing analyses. The $\sec Y$, tuf and stamp genes were additionally analyzed in the six samples from the experimental field selected for phytoplasma 16S rDNA sequence analysis, an additional three randomly selected from among the positive samples from the experimental field and three from Bačko Dobro Polje. In order to amplify the tuf gene, the fTufAy/rTufAy primer pair was used in direct PCR assays (Schneider and Gibb 1997), while direct PCR with an AYsecYF1/AYsecYR1 primer pair was performed for amplifying the $\sec Y$ gene (Lee et al. 2006). For amplification of stamp gene nested PCR assays were performed using Stamp-F/R0 primer pair in direct followed by Stamp-F1/R1 in nested reactions (Fabre et al. 2011b). The PCR mix composition for all reactions was as described previously, as well as PCR conditions (Fabre et al. 2011b; Lee et al. 2006; Schneider and Gibb 1997). The fTufAy/rTufAy, AYsecYF1/AYsecYR1 and Stamp-F1/R1 PCR products were sequenced in both directions with the primers applied for amplification (Macrogen Inc., Seoul, Korea). The obtained sequences were assembled and compared as described earlier. A 906 nt-long nucleotide sequence of the partial tuf gene, a 1,234 nt-long complete sequence of the $\sec Y$ gene and a $474 \mathrm{nt}-$ long nucleotide 
205

206

207

208

209

210

211

212

213

214

215

216

217

218

219

220

221

222

223

224

225

226

227

sequence of the partial stamp gene of the phytoplasma strain 429/19 from sugar beet were deposited in GenBank under accession numbers MT157234, MT157233 and MT783826, respectively. The obtained sequences were compared with available ones as reported before.

The tuf sequences were aligned with those of the strains representing three previously described tuf types, using ClustalX (Thompson et al. 1997), under MEGA version 7 (Kumar et al. 2016). The tuf gene sequences of strains CrHo13_1183, CrHo12_601 and CrHo12_650 (acc. numbers KJ469707, KJ469708 and KJ469709, respectively), representing those previously described as the ' $C a$. P. solani' tuf types tuf a, tuf b1 and tuf b2, respectively (Aryan et al., 2014), were added to the alignment, and putative restriction site maps were generated using the software pDRAW32 (http://www.acaclone.com/). In order to confirm virtual RFLP, the obtained fTufAy/rTufAy amplicons were subjected to RFLP analyses with the Tail restriction enzyme (Thermo Scientific, Vilnius, Lithuania). Restriction products were separated, stained and visualised as described above. To obtain better visualization of the stamp gene divergence among detected ' $\mathrm{Ca}$. P. solani' isolates, genealogical network was calculated in software TCS v.1.21 (Clement et al. 2000) using statistical parsimony with a confidence level of 93\% (Templeton et al. 1992). All stamp genotypes belonging to the stamp genetic clusters II tuf-b and III tuf-b that had been detected in Serbia were added to the analysis (Fabre et al. 2011; Cvrković et al. 2014).

The stamp sequences were aligned with those of the strains representing previously described stamp genotypes in Serbia. The stamp gene sequences of the isolates STOL Rqg50, Rpm35, Rqg31, Vv24 and HoC68 (genotype M5) (acc.nos. FN813261, KC703019, KC703015, KC703017, KC703022 and KP337316, respectively) were used for the genotyping of the obtained 'Ca. P. solani' isolates (Atanasova et al. 2015; Cvrković et al. 2014; Fabre et al. 2011b; Mitrović et al. 2016). 
In order to check over ' $\mathrm{Ca}$. P. solani' tuf and stamp genotypes in different hosts and geographic

229

230

231

232

233

234

235 areas we selected $40^{\prime} \mathrm{Ca}$. P. solani' strains from phytoplasma collection at the Laboratory of Phytopathology, Institute of Pesticides and Environmental Protection, Belgrade, Serbia, from different hosts and areas over the period 2009-2019, and included them in the tuf and stamp analyses (Table 1). Among the 40 ' $\mathrm{Ca}$. P. solani' strains, two were obtained from 10 and 20 sugar beet roots randomly collected from the locations Srem and Kačarevo (one per location), respectively, from those prepared for industrial procession and without symptom assessment. In strains that had not been identified earlier, 'Ca. P. solani' identification was confirmed as described above, and the tuf and stamp genes were determined for all samples as described above.

\section{RESULTS}

Disease symptoms. The first symptom of sugar beet rubbery taproot, usually appearing in the second half of July, is a loss of turgor in leaves during the hottest part of the day. It is followed by yellowing and, later, necrosis of the oldest leaves, starting from their margins (Fig. 1A). Eventually, all leaves become necrotic, which leads to the complete decline of the plant (Fig. 1B). Symptoms become obvious in August and stay visible until harvesting. Taproots of diseased plants wilt, become rubbery and stay without any rot symptoms until after plant decline (Fig. 1C). Sections of symptomatic taproots reveal no visual difference from those of healthy taproots, or any discoloration (Fig. 1D). However, symptomatic taproots in the field are prone to rotting after plant decline, due to the activity of saprobes. As a consequence, some of infected taproots, especially those infected in the early season, do not last until harvest. When diseased sugar beets 
250 are harvested, their rubbery taproots cannot be used for industry, as they cannot be sliced into 251 cossettes, which is why they have to be discarded.

Molecular analysis reveals 'Ca. P. solani' infection. Nested PCR reactions with the 253 phytoplasma-specific $\mathrm{R} 16 \mathrm{~F} 2 \mathrm{n} / \mathrm{R} 2$ primer pair resulted in an expected length fragment 254 amplification for phytoplasmas $(1.2 \mathrm{~kb})$ in all symptomatic samples of the sugar beet hybrid 255 Original, in all but one (29 out of 30) symptomatic samples of the other tested sugar beet hybrids 256 and in all three symptomatic samples from Bačko Dobro Polje. No amplification was obtained 257 from 20 asymptomatic samples of the hybrid Original, 20 asymptomatic or one symptomatic 258 sugar beet samples randomly collected from the other hybrids, one asymptomatic sample from 259 Bačko Dobro Polje, two SBR symptomatic samples from Germany and from the negative 260 controls.

261 All 62 positive samples, when R16F2n/R2 amplicons were subjected to RFLP analysis with 262 the TruI restriction enzyme, showed restriction profiles identical (data not shown) and referable 263 to the profile of ' $\mathrm{Ca}$. P. solani' (stolbur phytoplasma, 16SrXII-A ribosomal group) according to 264 the previously published phytoplasma classification system (Lee et al. 1998).

265 Sequences of the almost complete 16S ribosomal RNA gene, the internal spacer region and a 2665 ' portion of the $23 \mathrm{~S}$ ribosomal RNA gene were determined for 12 representative samples 267 amplified in direct PCR with a P1/P7 primer pair. Multiple sequence alignment showed that the 268 sequences of all Serbian ' $\mathrm{Ca}$. P. solani' samples were identical, and, when compared to the 269 available sequences, they were also identical with several other sequences of ' $\mathrm{Ca}$. P. solani', from 270 corn, grapevine, tobacco (from Serbia) and potato (from Russia), i.e. JQ730739, JQ730745, 271 JQ730746, JQ730750, JQ868436 and EU344884. 
'Ca. A. phytopathogenicus' assessment PCRs, using both Alb1/Oliv1 and Fra5/Fra4 primer

273 pairs, yielded amplicons of expected sizes (four amplicons ranging between 732 and 927bp with

274 Alb1/Oliv1, and 550bp with Fra5/Fra4 primer pairs), but only for the two SBR-positive controls

275 from Germany, while no amplification was obtained from any sugar beet sample from Serbia. For

276 the two SBR positive controls from Germany, amplified in direct PCR with the Fra5/Fra4 primer

277 pair, sequences of the partial 16S ribosomal RNA gene were determined. Multiple sequence

278 alignment showed that the obtained sequences for the two SBR strains from Germany were

279 mutually identical, and compared to available sequences they were identical to the sequences of

280 'Ca. A. phytopathogenicus' from the SBR-affected sugar beet from France (AY057392) and those

281 of four closely related proteobacteria from strawberry affected with strawberry marginal chlorosis

282 from Italy (DQ538379, DQ538378, DQ538377, DQ538375). The analyses confirmed the

283 identification of ' $\mathrm{Ca}$. A. phytopathogenicus' in positive controls obtained from the SBR-affected

284 sugar beet from Germany.

285 Non-ribosomal genes. With the AYsecYF1/R1 primer pair, expected amplicons of 286 approximately $1.2 \mathrm{~kb}$ in length were obtained for all 12 selected symptomatic sugar beet samples 287 in which 'Ca. P. solani' presence was confirmed with P1/P7 primers and a 16S rDNA sequence 288 was determined. Multiple sequence alignment showed that the determined $\sec Y$ gene sequences 289 for all 12 Serbian 'Ca. P. solani' samples were mutually identical, and compared to publicly 290 available sequences they were identical with four other sequences of ' $\mathrm{Ca}$. P. solani': three strains 291 from Serbia (strains 284/09, FO393427 and 142/09, JQ730747 both from tobacco, and strain 292 204/10, JX645766 from periwinkle) and one from Bosnia and Herzegovina (strain M7, 293 KU374896 from corn). 
Using the fTufAy/rTufAy and Stamp-F1/R1 primer pairs, the expected amplicons of approximately $950 \mathrm{bp}$ and $480 \mathrm{bp}$, respectively in length were obtained for 52 selected 'Ca. P. solani' infected sugar beets and other samples (Table 1). Sequences of a partial tuf and stamp genes were determined for all samples.

298 Multiple sequence alignment showed that the determined tuf gene sequences can be 299 discriminated in two genotypes with a single nucleotide polymorphism (SNP) difference. One 300 genotype was identical to a previously described ' $\mathrm{Ca}$. P. solani' tuf genotype tuf b1 (Aryan et al. 2014; Langer and Maixner 2004), but the other represents a new tuf genotype, since the SNP on position 174 after the tuf start codon ((G/A), which is synonymous (Glu) when translated) differentiates it from all genotypes described so far and those publicly available. Considering that the unique SNP affects a restriction site for the TaiI, SetI and HpyCH4IV restriction enzymes, and that the tuf c genotype was described previously for a genotype differentiated with the HpaII restriction enzyme (Langer and Maixner 2004), we named the new tuf genotype "tuf d". When compared to the sequences of the previously described ' $\mathrm{Ca}$. P. solani' tuf genotypes tuf b1, tuf b2 and tuf a (Aryan et al., 2014), the new genotype tuf d revealed one, two and three SNPs, respectively (Table 2). Virtual RFLP analysis demonstrated that the three restriction enzymes can differentiate the tuf $\mathrm{d}$ strains, the one prevalent in sugar beet, from all other publicly available selected ' $C a$. P. solani' tuf b and tuf d strains with the TaiI restriction enzyme confirmed virtual 313 RFLP results, allowing for rapid differentiation between the new tuf $d$ and other tuf types. The 314 difference shown in virtual RFLP analysis is clearly visible in the representative polyacrylamide 315 gel run after RFLP reaction (Fig. 2). 
The stamp gene sequences obtained from 52 samples in this work can be discriminated into six genotypes (Table 1, Fig. 3). Most of the sugar beets (12/14) bear STOL genotype. Per one sugar beet sample correspond to the Rqg50 and M5 genotypes. Genotype Rqg50 has shown widest host range being detected in as many as 9/12 plant species analysed in this study: carrot, parsley, tobacco, C. arvensis, grapevine, parsnip, celery, valerian and naturally infected periwinkle (Table 1, Fig. 3). Genotypes Rpm35 and Rqg31 were sporadically detected in celery, parsley and C. arvensis with no specific host preference or geographic pattern. In our study two

$323 \mathrm{Vv} 24$ isolates were detected in pepper and parsley (Table 1, Fig. 3). All sugar beet isolates 324 determined on the stamp gene as the STOL genotype are correlated to the newly detected tuf d 325 type, while the two samples bearing tuf b1 genotype corresponded to Rqg50 and M5. The same 326 situation was with parsnip and parsley. Unlike these samples, another four STOL isolates from 327 corn and pepper as well as other five stamp genotypes (Rqg50, Rpm35, Rqg31, Vv24 and M5) 328 are characterized on the tuf gene as the tuf b1 strains

329 Disease prevalence, susceptibility of sugar beet cultivars to RTD. Field evaluation in both years indicated significant differences amongst the hybrids in terms of mean disease prevalence (Fig. 4). In the both years Terranova was the most susceptible, Tesla, Eduarda and Original were moderately susceptible, while Tajfun and Nansen were the group of the least susceptible cultivars. Cultivars Nora and Leopolda were the most susceptible in 2018, with Nora showing a poor germination in addition. Therefore the two were replaced with Sioux and Sixtus which showed to be among the least susceptible in 2019. However, due to fact that both cultivar pairs were analysed for only one year, they were excluded from the statistical analyses.

Average RTD prevalences in the plots were $23.7 \%$ and $3.32 \%$, with maximal prevalences of 
Page 16 of 32

Živko Ćurčić

Plant Disease

339 prevalences in 2018 and 2019, given the occurrences per plot (Fig. 5), a clear pattern was

340 discerned in the distribution of high RTD prevalence plots, which were for both years most

341 prevalent at the borders of the experimental field.

\section{DISCUSSION}

345 Sugar beet RTD in Serbia was associated in the present study with ' $\mathrm{Ca}$. P. solani'. 'Ca. A. 346 phytopathogenicus' was not detected in any of the 134 symptomatic and asymptomatic sugar 347 beets collected in Serbia, which at the very least excludes it as the main etiological agent of RTD, 348 if present at all. Previously, RTD had been documented in literature in Serbia and neighboring 349 countries as a destructive, yield-reducing disease which appears periodically in epidemic scales, 350 with unknown etiology or associated to the abiotic factors, due to fact that no phytopathogenic 351 fungi or bacteria could be isolated (Marić 1974; Marić et al. 1970). Almost strict correlation 352 between the presence of ' $\mathrm{Ca}$. P. solani' in plants and their typical RTD symptomatology provides 353 strong evidence that ' $\mathrm{Ca}$. P. solani' is the causal agent of this economically damaging disease in 354 Serbia. While all 41 asymptomatic sugar beets tested negative, and 62 out of 63 symptomatic 355 sugar beets tested positive, it is possible that the one symptomatic sugar beet tested negative due 356 to its low phytoplasma titer, uneven distribution, the presence of PCR-inhibiting compounds or 357 other technical challenges. 'Ca. P. solani' was identified by using PCR amplification and 358 sequence analysis of $16 \mathrm{~S}$ rDNA, as well as the housekeeping gene tuf and a more variable single 359 copy $\sec Y$ and stamp genes.

360 'Ca. P. solani' has long been known as a widespread problem on other host plants (grown and 361 wild) in Serbia, but it has never been reported on sugar beet. It has been described on sugar beet 
362 in France, but not yet in terms of causing significant disease. Actually, 'Ca. P. solani' has been 363 occasionally (usually in fewer than $10 \%$ of SBR-affected samples) detected in SBR-affected 364 sugar beets in France (but not in Germany and Switzerland), besides its main pathogen ' $\mathrm{Ca}$. A. 365 phytopathogenicus', and it was not found to play a significant role in SBR epidemics (Gatineau et al. 2002; Sémétey et al. 2007b). Remarkably, the symptoms of 'Ca. P. solani' on sugar beet 367 described in this work in Serbia are strikingly different from those reported in France (Bressan et al. 2008).

The symptoms observed on RTD-affected sugar beets in Serbia differ in relation to the most 370 characteristic symptoms for the two diseases, namely rubbery taproot and no vascular 371 discoloration in RTD, in contrast to firm taproot and brownish vascular discoloration in SBR. 372 RTD affects the yield and physical property of the roots, i.e. their "sliceability". Although there 373 are no quantitative criteria to assess the physical properties of sugar beet roots, such as 374 sliceability, in case of high prevalence (more than 5\%), the RTD often results in a situation 375 whereby root quality does not match manufacturing requirements and therefore leads to the 376 rejection of a complete yield by the processing industry.

377 Bearing in mind that symptoms of RTD caused by ' $C a$. P. solani' on sugar beet in Serbia are 378 closer in similarity to those of sugar beet yellow wilt disease, caused by another phytoplasma 379 (16SrIII-J) in South America, than to those of SBR (Bennett and Munck 1946; Fernández et al. 2020; Vallejo 1970), notion of other diseases of unknown etiology with similar symptoms in 381 other parts of the world having a common causal agent-phytoplasma (e.g. the one reported in 382 Arizona, USA by Ruppel 1969) should be reconsidered. In terms of temporal (time of symptom appearance and recurrent epidemics) and in-field spatial distribution (more severe nearer to the 384 field borders), RTD is reminiscent of other ' $\mathrm{Ca}$. P. solani'-induced diseases of annual crops in 
385

386

387

388

389

Serbia, such as corn reddening and stolbur on pepper (Duduk and Bertaccini 2006). Since the RTD, similarly to other diseases of annual crops associated with ' $\mathrm{C} a$. P. solani', appears with higher intensity in dry and hot years, and in temperate regions of the Pannonian Plain, it is expected to be strongly affected by climate changes, such as more frequent and intense summer heatwaves and droughts (Spinoni et al. 2015), and it raises the question as to whether the disease should be expected to reemerge more often and with greater severity in the future. Moreover, it raises concerns over its spreading to other regions of Europe under an enduring trend of climate change, both where ' $\mathrm{C} a$. P. solani' is already present on sugar beet or on other hosts. The results of this study suggest that differences in hybrid susceptibility constitute a factor that should be taken into account when developing a strategy to control sugar beet RTD.

Sequence analysis of $\sec Y$ gene revealed no variability among 12 Serbian ' $\mathrm{Ca}$. P. solani' strains from sugar beet and was therefore not applied for the analyses of other samples. The tuf gene analysis revealed two stolbur tuf genotypes in Serbia. Beside the already reported one tuf $b$ (b1) type, so far associated in Serbia with C. arvensis and Crepis foetida as phytoplasma infection sources (Kosovac et al. 2019), a new and distinct tuf genotype (named tuf d) was prevalent in sugar beet and present in Apiaceae. As tuf gene sequence variability has been reported to correlate with the epidemiological cycle and reservoir plant host (Aryan et al. 2014; Kosovac et al. 2016; Langer and Maixner 2004), the new tuf genotype raises the question as to whether the tuf $d$ strains share biology with the tuf $a / b 2$ (nettle), tuf $b(b 1)$ or with the one reported in France and associated with sugar beet/P. leporinus.

The most prevalent stamp genotype in analyzed sugar beet samples, STOL, had been initially isolated from Capsicum annuum from Serbia and associated with H. obsoletus ex C. arvensis (Aleksić et al. 1967; Fabre et al. 2011b). More recently it was reported in Serbia within the 
408 epidemiologies of Bois noir, related to cixiids Reptalus panzeri and H. obsoletus ex C. foetida, 409 and potato stolbur (Cvrković et al. 2014; Kosovac et al., 2019; Mitrović et al. 2016). Other two 410 genotypes detected in per one sugar beet sample Rqg50 and M5, were both previously associated 411 with the same hosts, grapevine and potato, and corresponding vector $H$. obsoletus ex $C$. arvensis 412 (Atanasova et al., 2015; Mitrović et al., 2016). Additionally, genotype Rqg50 had been linked 413 with two other vectors, $R$. panzeri and $R$. quiniqueostatus (Cvrković et al. 2014). In this study this 414 genotype showed the widest host range, being detected in as many as 9/12 plant species analysed: 415 carrot, parsley, tobacco, bindweed, grapevine, parsnip, celery, valerian and naturally infected 416 periwinkle (Table 1). Genotypes Rpm35 and Rqg31 were in this work sporadically detected in 417 celery, parsley and C. arvensis with no specific host preference or geographic pattern, while both 418 stamp genotypes had also been associated with Bois noir and potato stolbur and H. obsoletus ex 419 C. arvensis and R. panzeri as vectors (Cvrković et al. 2014; Mitrović et al. 2016). Stamp 420 genotype Vv24 had been in the region mainly associated with grapevine (Atanasova et al. 2015;

421 Cvrkovic et al. 2014; Kosovac et al. 2016), while in our study two Vv24 isolates were detected in 422 pepper and parsley (Table 1). The six stamp genotypes obtained in this work (i.e. STOL, Rqg50, 423 Rpm35, Rqg31, Vv24 and M5) (Table 1, Fig. 3), had been all described previously in Serbia 424 (Atanasova et al. 2015; Cvrković et al. 2014; Fabre et al. 2011b; Mitrović et al. 2014). Typing of 425 the stamp gene revealed affiliation of all analysed samples to the tuf $b(b 1)$ epidemiological 426 pathway (Atanasova et al. 2015; Cvrković et al. 2014), whether they are belonging to the tuf $427 \quad b(b 1)$ or the new tuf $d$ genotype. However, differentiation of strains from sugar beet and the ones 428 from Apiaceae based of tuf gene sequence analyses was corroborated by analyses based on stamp 429 gene. Therefore, the main tasks in the future epidemiological research should be tracing of the 430 insect vectors employed in different ' $\mathrm{Ca}$. P. solani' epidemiological routs in Serbia and 
431 confirmation of their role by transmission trials, along with the survey on the presence of $P$.

432 leporinus, the vector of both, SBR and 'Ca. P. solani' on sugar beet in France.

433 Clarification of the etiology of RTD as a long-known and economically important disease in

434 Serbia and neighbouring countries as a result of this work is certainly the first step towards 435 disease management. Bearing in mind complex ecology of ' $\mathrm{Ca}$. P. solani', the acquired 436 knowledge about the genetic relationship between the ' $\mathrm{Ca}$. P. solani' strain prevalent in sugar beet 437 in Serbia and other strains on different plant species is crucial for further epidemiological work to 438 identify insect vectors responsible for the disease, and possible plant reservoir hosts in the area. 439 This is even more important, since the observed frequency of high prevalence plots at field 440 borders suggests infections through vectors migrating from outside the field. Although the 441 significance of finding a distinct genotype of the tuf gene is still to be completely evaluated, the 442 unique property of the tuf gene of the strain prevalent in sugar beet in Serbia, differentiable by 443 RFLP, can certainly help in further epidemiological work seeking to identify insect vectors and 444 possible plant reservoir hosts of this prokaryote with an extremely wide host range.

\section{ACKNOWLEDGMENTS}

447 We thank agronomist Živko Vasin for helpful suggestions, sharing important experience and 448 technical assistance in the field.

450 LITERATURE CITED

452 Aleksić, Ž., Šutić, D., and Aleksić, D. 1967. Transmission intensity of stolbur virus by means of 453 Hyalesthes obsoletus Sign. on some host plants. Zaštita bilja. 93-95:67-73. 
454 Aryan, A., Brader, G., Mörtel, J., Pastar, M., and Riedle-Bauer, M. 2014. An abundant

455 'Candidatus Phytoplasma solani' tuf $\mathrm{b}$ strain is associated with grapevine, stinging nettle and 456 Hyalesthes obsoletus. Eur J Plant Pathol 140:213-227.

457 Atanasova, B., Jakovljević, M., Spasov, D., Jović, J., Mitrović, M., Toševski, I., and Cvrković, T. 458 2015. The molecular epidemiology of bois noir grapevine yellows caused by 'Candidatus 459 Phytoplasma solani' in the Republic of Macedonia. Eur J Plant Pathol 142:759-770.

460 Bennett, C. W., and Munck, C. 1946. Yellow wilt of sugar beet in Argentina. J Agric Res 73:4546164.

462 Bressan, A., Sémétey, O., Nusillard, B., Clair, D., and Boudon-Padieu, E. 2008. Insect Vectors 463 (Hemiptera: Cixiidae) and Pathogens Associated with the Disease Syndrome "Basses Richesses" 464 of Sugar Beet in France. Plant Dis 92:113-119.

465 Bressan, A., Holzinger, W. E., Nusillard, B., Sémétey, O., Gatineau, F., Simonato, M., and 466 Boudon-Padieu, E. 2009. Identification and biological traits of a planthopper from the genus 467 Pentastiridius (Hemiptera: Cixiidae) adapted to an annual cropping rotation. Eur J Entomol $468 \quad 106: 405-413$.

469 Bressan, A., Terlizzi, F., and Credi, R. 2012. Independent Origins of Vectored Plant Pathogenic 470 Bacteria from Arthropod-Associated Arsenophonus Endosymbionts. Microb Ecol 63:628-638.

471 Castro, S., Hepp, R., and Romero, J. 2000. La marchitez amarilla de la remolacha azucarera de 472 Chile es producida por un fitoplasma del grupo 16SrIII. In Proceedings of the Tenth Congress of 473 the Sociedad Española de Fitopatología, p. 3-6.

474 Christova, E. 1950. The top rot in sugar beet in this country. Spisanie na naucno-izsledovatelskite 475 instituti pri ministarstvata na zemedelieto i gorite. 4:57-62. 
476 Clement, M., Posada, D., and Crandall, K. A. 2000. TCS: a computer program to estimate gene 477 genealogies. Mol Ecol 9:1657-1659.

478 Cvrković, T., Jović, J., Mitrović, M., Krstić, O., and Toševski, I. 2014. Experimental and 479 molecular evidence of Reptalus panzeri as a natural vector of bois noir. Plant Pathol 63:42-53.

480 Deng, S., and Hiruki, C. 1991. Amplification of 16S rRNA genes from culturable and 481 nonculturable mollicutes. J Microbiol Meth 14:53-61.

482 Doyle, J.J., and Doyle, J.L. 1990. Isolation of plant DNA from fresh tissue. Focus 12:13-15.

483 Duduk, B., Botti, S., Ivanović, M., Krstić, B., Dukić, N., and Bertaccini, A. 2004. Identification 484 of phytoplasmas associated with grapevine yellows in Serbia. J Phytopathol 152:575-579.

485 Duduk, B., and Bertaccini, A. 2006. Corn with Symptoms of Reddening: New Host of Stolbur 486 Phytoplasma. Plant Dis 90:1313-1319.

487 Fabre, A., Balakishiyeva, G., Ember, I., Omar, A., Ács, Z., Kolber, M., Kauzner, L., Della 488 Bartola, M., Danet, J.-L., and Foissac, X. 2011a. StAMP encoding the antigenic membrane 489 protein of stolbur phytoplasma is useful for molecular epidemiology. B Insectol 64 (Supplement): $490 \quad$ S21-S22.

491 Fabre, A., Danet, J.-L., and Foissac, X. 2011b. The stolbur phytoplasma antigenic membrane 492 protein gene stamp is submitted to diversifying positive selection. Gene 472:37-41.

493 Fankhauser, P. 2019. Ist das der Todesstoss? - Zuckerrüben / Die neue Rübenkrankheit mit dem 494 Namen Syndrome Basses Richesses (SBR) sorgt in der Westschweiz für grosse Verluste. Bauern 495 Zeitung :29.

496 Fernández, F. D., Guzmán, F. A., Baffoni, P., Reinoso, L., Kiehr, M., Delhey, R., Favere, V. M., 497 Galdeano, E., and Conci, L. R. 2020. Phytoplasmas of subgroup 16SrIII-J associated with Beta 498 vulgaris in Argentina. Trop Plant Pathol https://doi.org/10.1007/s40858-019-00317-9 
499 Fiore, N., González, X., Zamorano, A., Quiroga, N., Paillalef, R., and Pino, A. M. 2015.

500 Phytoplasmas associated with yellow wilt disease of sugar beet in Chile. Phytopathogenic

501 Mollicutes 5:S63-S64.

502 Gatineau, F., Larrue, J., Clair, D., Lorton, F., Richard-Molard, M., and Boudon-Padieu, E. 2001.

503 A New Natural Planthopper Vector of Stolbur Phytoplasma in the Genus Pentastiridius

504 (Hemiptera: Cixiidae). Eur J Plant Pathol 107:263-271.

505 Gatineau, F., Jacob, N., Vautrin, S., Larrue, J., Lherminier, J., Richard-Molard, M., and Boudon-

506 Padieu, E. 2002. Association with the Syndrome "Basses Richesses" of Sugar Beet of a

507 Phytoplasma and a Bacterium-Like Organism Transmitted by a Pentastiridius sp. Phytopathology $508 \quad 92: 384-392$.

509 Genov, N., Mitrović, J., Genov, M., and Duduk, B. 2014. First Report of Corn Reddening Caused 510 by 'Candidatus Phytoplasma solani' in Bulgaria. Plant Dis 98:991-991.

511 Jović, J., Cvrković, T., Mitrović, M., Krnjajić, S., Petrović, A., Redinbaugh, M. G., Pratt, R. C.,

512 Hogenhout, S. A., and Toševski, I. 2009. Stolbur phytoplasma transmission to maize by Reptalus

513 panzeri and the disease cycle of maize redness in Serbia. Phytopathology 99:1053-1061.

514 Kosovac, A., Radonjić, S., Hrnčić, S., Krstić, O., Toševski, I., and Jović, J. 2016. Molecular

515 tracing of the transmission routes of bois noir in Mediterranean vineyards of Montenegro and

516 experimental evidence for the epidemiological role of Vitex agnus-castus (Lamiaceae) and

517 associated Hyalesthes obsoletus (Cixiidae). Plant Pathol 65:285-298.

518 Kosovac, A., Jakovljević, M., Krstić, O., Cvrković, T., Mitrović, M., Toševski, I., and Jović, J.

519 2019. Role of plant-specialized Hyalesthes obsoletus associated with Convolvulus arvensis and

520 Crepis foetida in the transmission of 'Candidatus Phytoplasma solani'-inflicted bois noir disease

521 of grapevine in Serbia. Eur J Plant Pathol 153:183-195. 
522 Kumar, S, Stecher, G, and Tamura, K. 2016. MEGA7: Molecular Evolutionary Genetics Analysis

523 version 7.0 for bigger datasets. Mol Biol Evol 33:1870-1874

524 Langer, M., and Maixner, M. 2004. Molecular characterisation of grapevine yellows associated

525 phytoplasmas of the stolbur-group based on RFLP-analysis of non-ribosomal DNA. Vitis

$526 \quad 43: 191-199$.

527 Lee, I., Bertaccini, A., Vibio, M., and Gundersen, D. 1995. Detection of multiple phytoplasmas in 528 perennial fruit trees with decline symptoms in Italy. Phytopathology 85:728-735.

529 Lee, I.-M., Gundersen-Rindal, D. E., Davis, R. E., and Bartoszyk, I. M. 1998. Revised

530 classification scheme of phytoplasmas based on RFLP analyses of 16S rRNA and ribosomal

531 protein gene sequences. Int J Syst Evol Micr 48:1153-1169.

532 Lee, I.-M., Zhao, Y., and Bottner, K. D. 2006. SecY gene sequence analysis for finer

533 differentiation of diversestrains in the aster yellows phytoplasma group. Mol Cell Probe 20:8753491.

535 Marić, A. 1974. Bolesti šećerne repe. Poljoprivredni Fakultet, Novi Sad.

536 Marić, A., Rudić, E., and Avdalović, T. 1970. Problem uvenuća biljaka i truleži korena šećerne 537 repe u nekim rejonima Jugoslavije. Savremena Poljoprivreda 18:241-252.

538 Martinović, M., and Bjegović, P. 1950. O nekim bolestima i štetočinama utvrdjenim u NR Srbiji 539 u 1949 godini. Zaštita bilja 2:59-68.

540 Medić Pap, S., Gvozdanović Varga, J., Červenski, J., Stepanović, J., Rekanović, E., Stepanović, 541 M., and Duduk, B. 2017. First Report of 'Candidatus Phytoplasma solani' Infecting Parsnip in 542 Serbia. Plant Dis 102:1026-1026.

543 Mitrović, J., Pavlović, S., and Duduk, B. 2013. Survey and multigene characterization of stolbur 544 phytoplasmas on various plant species in Serbia. Phytopathologia Mediterranea 52:8. 
545 Mitrović, J., Siewert, C., Duduk, B., Hecht, J., Mölling, K., Broecker, F., Beyerlein, P., Büttner,

546 C., Bertaccini, A., and Kube, M. 2014. Generation and Analysis of Draft Sequences of 'Stolbur'

547 Phytoplasma From Multiple Displacement Amplification Templates. J Mol Microbiol Biotechnol $548 \quad 24: 1-11$.

549 Mitrović, M., Jakovljević, M., Jović, J., Krstić, O., Kosovac, A., Trivellone, V., Jermini, M., 550 Toševski, I., and Cvrković, T. 2016. 'Candidatus phytoplasma solani' genotypes associated with 551 potato stolbur in Serbia and the role of Hyalesthes obsoletus and Reptalus panzeri (hemiptera, 552 cixiidae) as natural vectors. Eur J Plant Pathol 144:619-630.

553 Mori, N., Mitrović, J., Smiljković, M., Duduk, N., Paltrinieri, S., Bertaccini, A., and Duduk, B. 554 2013. Hyalesthes obsoletus in Serbia and its role in the epidemiology of corn reddening. B 555 Insectol 66:245-250.

556 Murolo, S., and Romanazzi, G. 2015. In-vineyard population structure of 'Candidatus 557 Phytoplasma solani' using multilocus sequence typing analysis. Infect Genet Evol 31:221-230. 558 Racovita, A. 1959. Noi cercetari privind gomoza sfeclei de zahar. Extras din Lucră rile 559 Institutului de cercetări alimentare 3:269-296.

560 Richard-Molard, M., Garraessus, S., Malatesta, G., Orny, G., Valentin, P., Lemaire, O., Reinbold, 561 C., Gesrt, M., Blech, F., Fonne, G., Putz, C., Grousson, C., and Boudon-Padieu, E. 1995. Le 562 syndrome des basses richesses-Investigations au champ et tentatives d'identification de l'agent 563 pathogène et du vecteur. In Proceedings of the $58^{\text {th }}$ Congres de L'Institut International de 564 Recherches Betteravières, Bruxelles, Dijon-Beaune, France, pp. 299-309.

565 Ruppel, E. G. 1969. Diseases of Sugarbeet in Arizona. The Plant Disease Reporter 53:56-58.

566 Schneider, B., Seemueller, E., Smart, C. D., and Kirkpatrick, B. C. 1995. E6-Phylogenetic 567 classification of plant pathogenic mycoplasma-like organisms or phytoplasmas. In S. Razin and J. 
568 G. Tully (Eds.), Molecular and diagnostic procedures in mycoplasmology, Academic Press, 569 Vol.1:369-380.

570 Schneider, B., and Gibb, K. S. 1997. Sequence and RFLP analysis of the elongation factor Tu 571 gene used in differentiation and classification of phytoplasmas. Microbiology 143:3381-3389.

572 Schröder, M., Rissler, D., and Schrameyer, K. 2012. “Syndrome des Basses Richesses”(SBR)— 573 erstmaliges Auftreten an Zuckerrübe in Deutschland. Journal fur Kulturpflanzen-Journal of 574 Cultivated Plants 64:396.

575 Sémétey, O., Bressan, A., Gatineau, F., and Boudon-Padieu, E. 2007a. Development of a specific 576 assay using RISA for detection of the bacterial agent of 'basses richesses' syndrome of sugar beet 577 and confirmation of a Pentastiridius sp. (Fulgoromopha, Cixiidae) as the economic vector. Plant 578 Pathol 56:797-804.

579 Sémétey, O., Bressan, Alberto, Richard-Molard, M., and Boudon-Padieu, E. 2007b. Monitoring 580 of proteobacteria and phytoplasma in sugar beets naturally or experimentally affected by the 581 disease syndrome 'Basses richesses'. Eur J Plant Pathol 117:187-196.

582 Spinoni, J., Naumann, G., Vogt, J., and Barbosa, P. 2015. European drought climatologies and 583 trends based on a multi-indicator approach. Global Planet Change 127:50-57.

584 Staden, R., Beal, K. F., and Bonfield, J. K. 2000. The Staden package. Methods Mol Biol $585 \quad 132: 115-130$.

586 Suhov, K. S., and Vovk, A. A. 1949. Stolbur rasienovüh. (Izd. Akad.Nauk. SSSR,Moskva587 Leningrad) (in Russian).

588 Templeton, A. R., Crandall, K. A., and Sing, C. F. 1992. A cladistic analysis of phenotypic 589 associations with haplotypes inferred from restriction endonuclease mapping and DNA sequence 590 data. III. Cladogram estimation. Genetics 132:619-633. 
591 Thompson, J.D., Gibson, T.J., Plewniak, F., Jeanmougin, F., Higgins, D.G. 1997. The Clustal X 592 windows interface: flexible strategies for multiple sequence alignment aided by quality analysis 593 tools. Nucleic Acids Res 24: 4876-4882.

594 Vallejo, M. 1970. Yellow wilt of sugar beet hi Chile. Savremena Poljoprivreda 18:253-255.

595 Zreik, L., Bové, J. M., and Garnier, M. 1998. Phylogenetic characterization of the bacterium-like 596 organism associated with marginal chlorosis of strawberry and proposition of a Candidatus taxon 597 for the organism, 'Candidatus Phlomobacter fragariae'. Int J Syst Bacteriol 48:257-261. 
598 Table 1. 'Ca. P. solani' tuf and stamp genotypes detected in RTD affected sugar beet and strains 599 from other hosts

\begin{tabular}{|c|c|c|c|c|c|c|}
\hline & Host & Year & Locality & tuf type & $\begin{array}{c}\text { Stamp } \\
\text { genotype* }\end{array}$ & Reference \\
\hline $9 x$ & sugar beet & 2019 & Rimski Šančevi & $\mathrm{d}$ & STOL & This paper \\
\hline \multirow[t]{6}{*}{$2 x$} & sugar beet & 2019 & Bačko Dobro Polje & d & STOL & This paper \\
\hline & sugar beet & 2019 & Bačko Dobro Polje & b1 & M5 & This paper \\
\hline & sugar beet & 2019 & Kačarevo & d & STOL & This paper \\
\hline & sugar beet & 2019 & Srem & b1 & Rqg50 & This paper \\
\hline & carrot & 2010 & Begeč & b1 & Rqg50 & Mitrović et al. 2013 \\
\hline & parsley & 2009 & Pančevo & $d$ & STOL & Mitrović et al. 2013 \\
\hline \multirow[t]{6}{*}{$8 X$} & parsley & 2009 & Pančevo & b1 & Rqg50 & Mitrović et al. 2013 \\
\hline & parsley & 2009 & Pančevo & b1 & Vv24 & Mitrović et al. 2013 \\
\hline & parsley & 2009 & Pančevo & b1 & $\begin{array}{c}284 / 09 \\
\text { (Rpm35) }\end{array}$ & Mitrović et al. 2013 \\
\hline & pepper & 2010 & Begeč & b1 & Vv24 & Mitrović et al. 2013 \\
\hline & pepper & 2011 & Pirot & b1 & STOL & This paper \\
\hline & tobacco & 2010 & Inđija & b1 & Rqg50 & Mitrović et al. 2013 \\
\hline \multirow[t]{6}{*}{$2 X$} & tobacco & 2010 & Bavanište & b1 & Rqg50 & Mitrović et al. 2013 \\
\hline & convolvulus & 2017 & Montenegro & b1 & Rqg50 & This paper \\
\hline & convolvulus & 2018 & Pančevo & b1 & $\begin{array}{l}231 / 09 \\
\text { (Rqg31) }\end{array}$ & This paper \\
\hline & convolvulus & 2018 & Leskovac & b1 & Rqg50 & This paper \\
\hline & grapevine & 2010 & Aleksandrovac & b1 & Rqg50 & Mitrović et al. 2013 \\
\hline & grapevine & 2010 & Bela Crkva & b1 & Rqg50 & Mitrović et al. 2013 \\
\hline $3 X$ & parsnip & 2016 & Rimski Šančevi & $d$ & STOL & Medić Pap et al. 2017 \\
\hline $3 x$ & parsnip & 2016 & Rimski Šančevi & b1 & Rqg50 & Medić Pap et al. 2017 \\
\hline
\end{tabular}


Page $\mathbf{2 9}$ of $\mathbf{3 2}$

Živko Ćurčić

Plant Disease

\begin{tabular}{|c|c|c|c|c|c|c|}
\hline & corn & 2009 & Perlez & b1 & STOL & Mitrović et al. 2013 \\
\hline & corn & 2013 & Bulgaria & b1 & STOL & Genov et al. 2014 \\
\hline & corn & 2013 & Debeljača & b1 & STOL & This paper \\
\hline \multirow[t]{4}{*}{$2 X$} & celery & 2013 & Svilajnac & b1 & Rqg50 & This paper \\
\hline & celery & 2013 & Svilajnac & b1 & $\begin{array}{c}284 / 09 \\
\text { (Rpm35) }\end{array}$ & This paper \\
\hline & celery & 2013 & Paraćin & b1 & $\begin{array}{c}231 / 09 \\
\text { (Rqg31) }\end{array}$ & This paper \\
\hline & valerian & 2009 & Pančevo & b1 & Rqg50 & Mitrović et al. 2013 \\
\hline $2 X$ & periwinkle & 2019 & Belgrade & b1 & Rqg50 & This paper \\
\hline
\end{tabular}


Page $\mathbf{3 0}$ of $\mathbf{3 2}$

Plant Disease

602 Table 2. Differential nucleotides of the four tuf types and SNP positions

\begin{tabular}{ccccc}
\hline Strain (Acc. No.) & Tuf genotype & 174 - Tail (aa) & 666 - Hpall (aa) & 727 (aa) \\
\hline CrHo13_1183 (KJ469707) & a & A (Glu) & C (Thr) & G (Val) \\
CrHo12_601 (KJ469708) & b1 & A (Glu) & T (Thr) & A (Ale) \\
CrHo12_650 (KJ469709) & b2 & A (Glu) & T (Thr) & G (Val) \\
429/19 (MT157234) & d & G (Glu) & T (Thr) & A (Ale) \\
\hline
\end{tabular}


603 Fig. 1. Symptoms of sugar beet rubbery taproot disease. A, Yellowing of the oldest leaves. B, complete plant decline

604 (left). C, rubbery taproot. D, Sections of symptomatic taproots (left) show no difference to those of healthy taproots 605 (right) or discoloration.

607 Fig. 2. Analysis of the fTufAy/rTufAy amplicon. A, Restriction map showing positions of restriction enzyme 608 recognition sites in the tuf gene of ' $\mathrm{Ca}$. P. solani' tuf types a, b and d. Differential recognition sites are indicated by arrows, while all other recognition sites are present in all tuf types assessed. Numbers are nucleotide positions

610 counted from the beginning of the fTufAy/rTufAy amplicon. B, Representative virtual and actual gels showing 611 patterns of 'Ca. P. solani' tuf types a, b and d digested with the Tail restriction enzyme. Fragment sizes of marker and the obtained fragments are indicated in bp. Reference strain sequences for tuf types in virtual RFLP are indicated in Table 2.

Fig. 3. Genealogical network based on parsimony analysis obtained for six 'Ca. P. solani' stamp genotypes detected in this study: STOL, Rqg50, Rpm35, Rqg31, Vv24 and M5, supplemented with additional genotype BG4560 (acc. no. FN813252) previously detected in Serbia (Cvrković et al., 2014), but not found during this study. Each of the seven stamp genotypes is represented with a circle proportional in size to the number of belonging isolates. Colors of the circle sections correspond to the specific host plant as given in the legend. Red dashed line indicates on the isolate group that corresponds to the newly detected tuf $\mathrm{d}$ genotype. Interconnecting dots represent nucleotide differences between genotypes; more than 1 nucleotide difference is shown with corresponding number and 622 abbreviation "nt".

Fig 4. Mean prevalence of RTD on sugar beet hybrids. Different lowercase letters indicate significant $(\mathrm{P}<0.05)$ 625 differences in RTD prevalence. Vertical bars represent standard errors.

627 Fig 5. Schematic representation of the map of the experimental field. Each rectangle represents a plot, while numbers 628 and coloured rectangles represent prevalence (in \%) in each plot. Empty rectangles in 2018 represent plots with poor 629 germination, excluded from analyses. 
Page $\mathbf{3 2}$ of $\mathbf{3 2}$

Plant Disease

630 

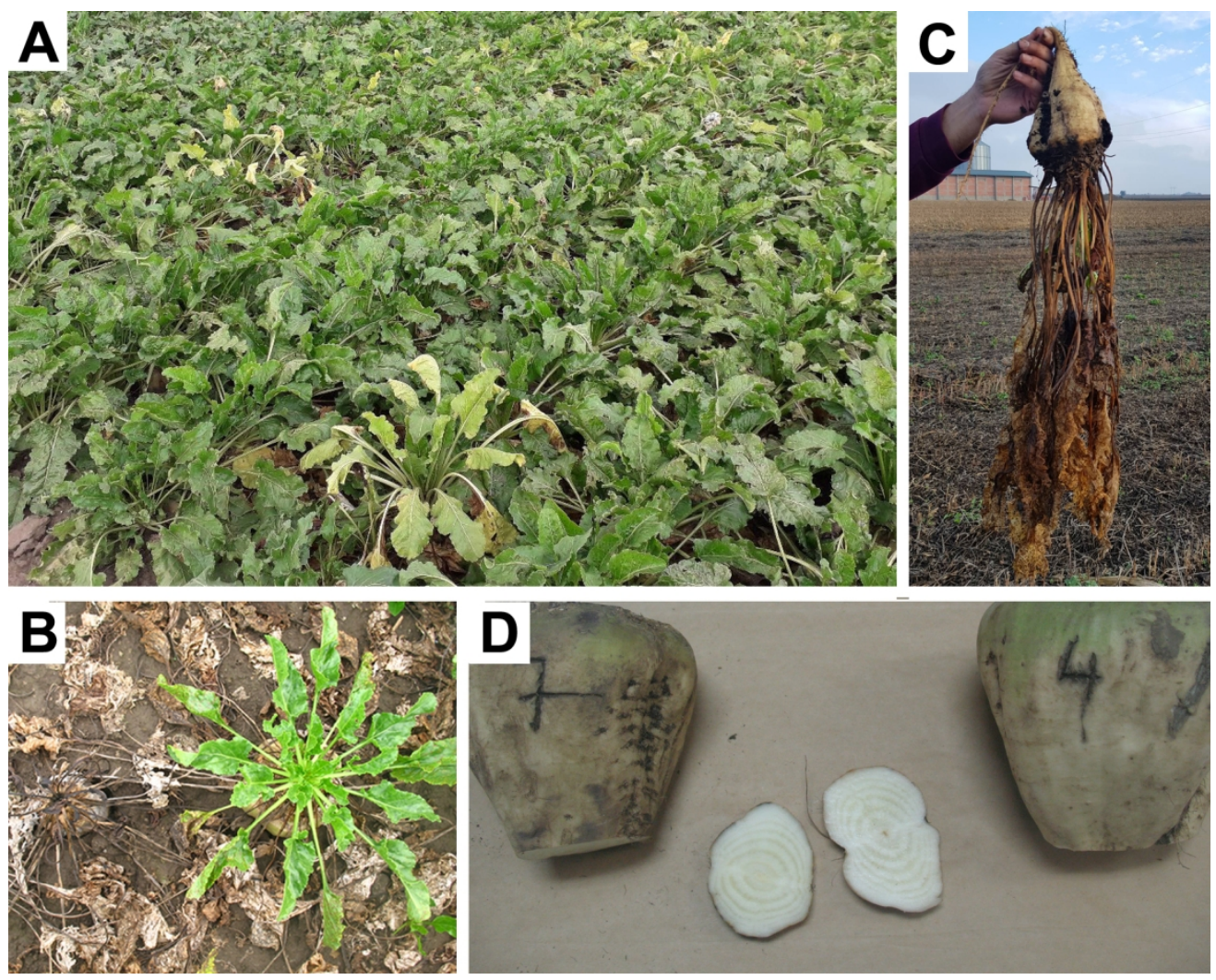

Fig. 1. Symptoms of sugar beet rubbery taproot disease. A, Yellowing of the oldest leaves. B, complete plant decline (left). C, rubbery taproot. D, Sections of symptomatic taproots (left) show no difference to those of healthy taproots (right) or discoloration.

$74 \times 59 \mathrm{~mm}(600 \times 600 \mathrm{DPI})$ 
A

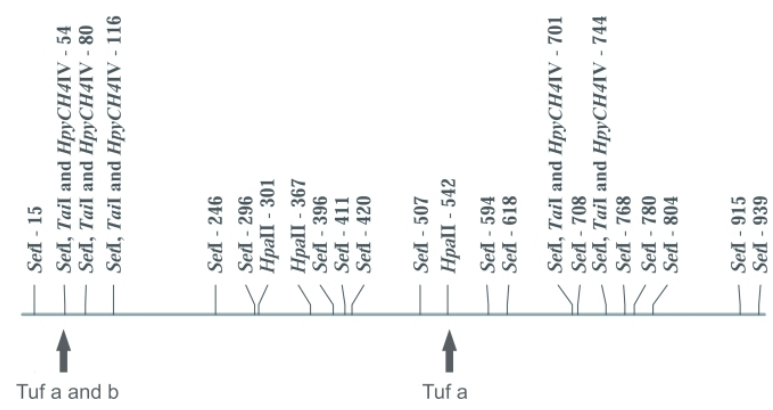

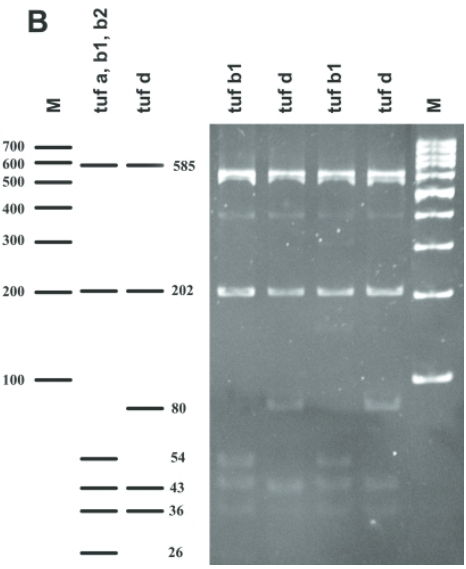

Fig. 2. Analysis of the fTufAy/rTufAy amplicon. A, Restriction map showing positions of restriction enzyme recognition sites in the tuf gene of 'Ca. P. solani' tuf types $\mathrm{a}, \mathrm{b}$ and d. Differential recognition sites are indicated by arrows, while all other recognition sites are present in all tuf types assessed. Numbers are nucleotide positions counted from the beginning of the fTufAy/rTufAy amplicon. B, Representative virtual and actual gels showing patterns of 'Ca. P. solani' tuf types $a, b$ and d digested with the TaiI restriction enzyme. Fragment sizes of marker and the obtained fragments are indicated in bp. Reference strain sequences for tuf types in virtual RFLP are indicated in Table 2.

$268 \times 116 \mathrm{~mm}(600 \times 600 \mathrm{DPI})$ 


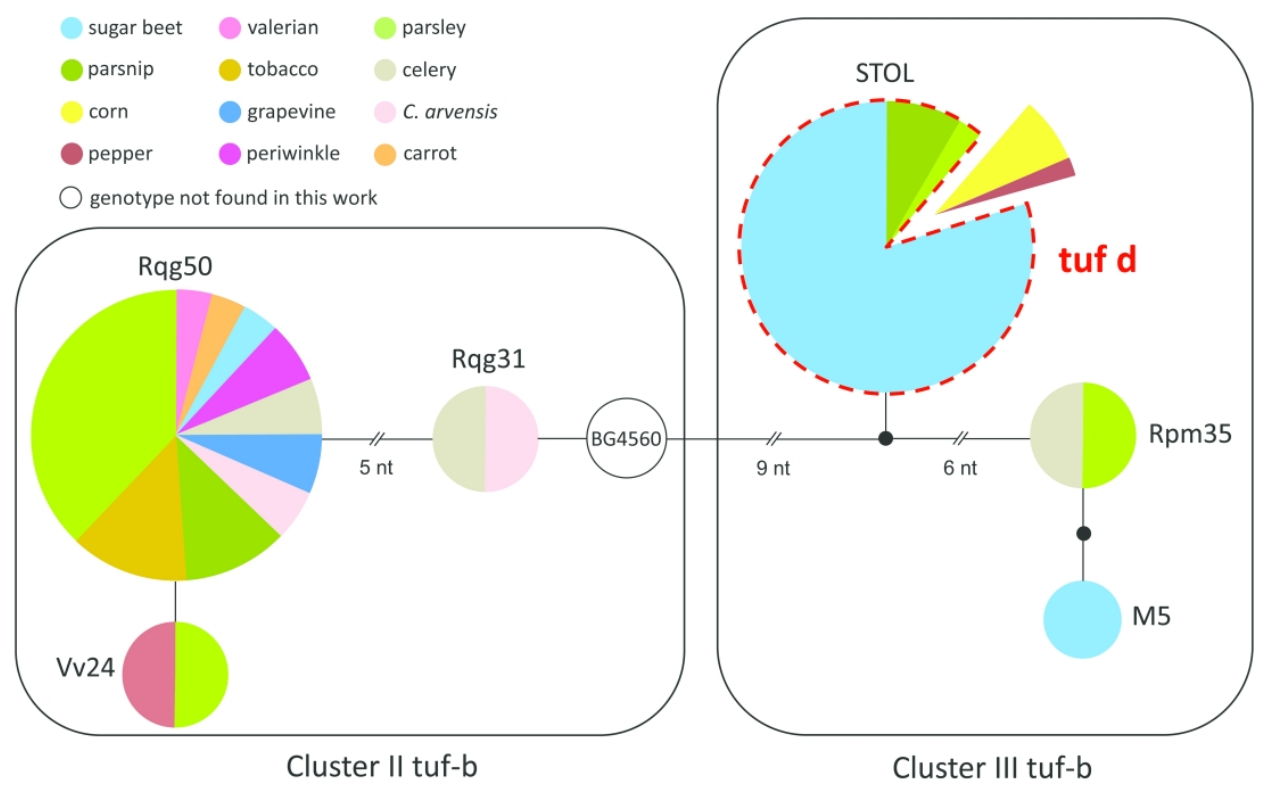

Fig. 3. Genealogical network based on parsimony analysis obtained for six 'Ca. P. solani' stamp genotypes detected in this study: STOL, Rqg50, Rpm35, Rqg31, Vv24 and M5, supplemented with additional genotype BG4560 (acc. no. FN813252) previously detected in Serbia (Cvrković et al., 2014), but not found during this study. Each of the seven stamp genotypes is represented with a circle proportional in size to the number of belonging isolates. Colors of the circle sections correspond to the specific host plant as given in the legend.

Red dashed line indicates on the isolate group that corresponds to the newly detected tuf $d$ genotype. Interconnecting dots represent nucleotide differences between genotypes; more than 1 nucleotide difference is shown with corresponding number and abbreviation "nt". 

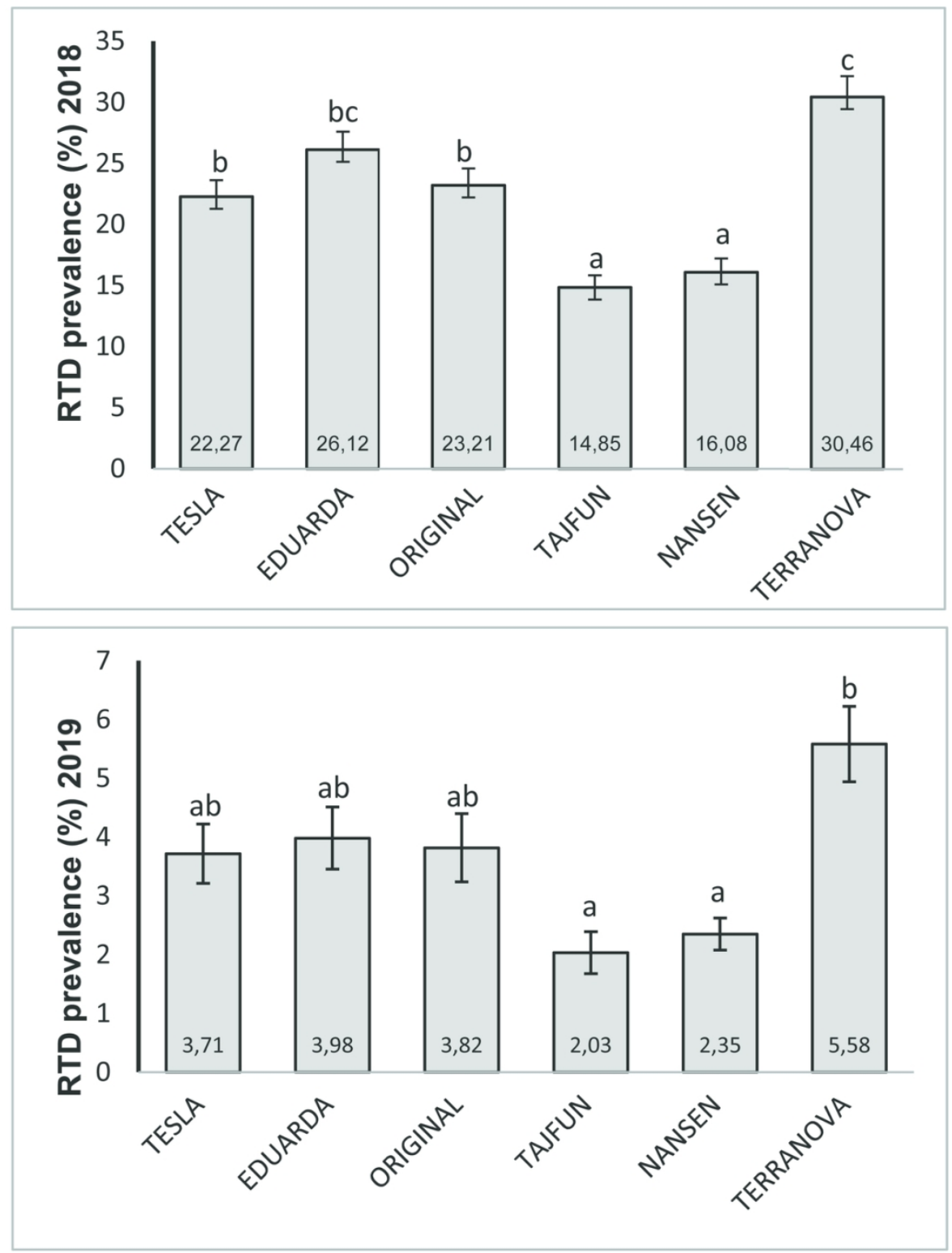

Fig 4. Mean prevalence of RTD on sugar beet hybrids. Different lowercase letters indicate significant $(\mathrm{P}<$ 0.05 ) differences in RTD prevalence. Vertical bars represent standard errors. 

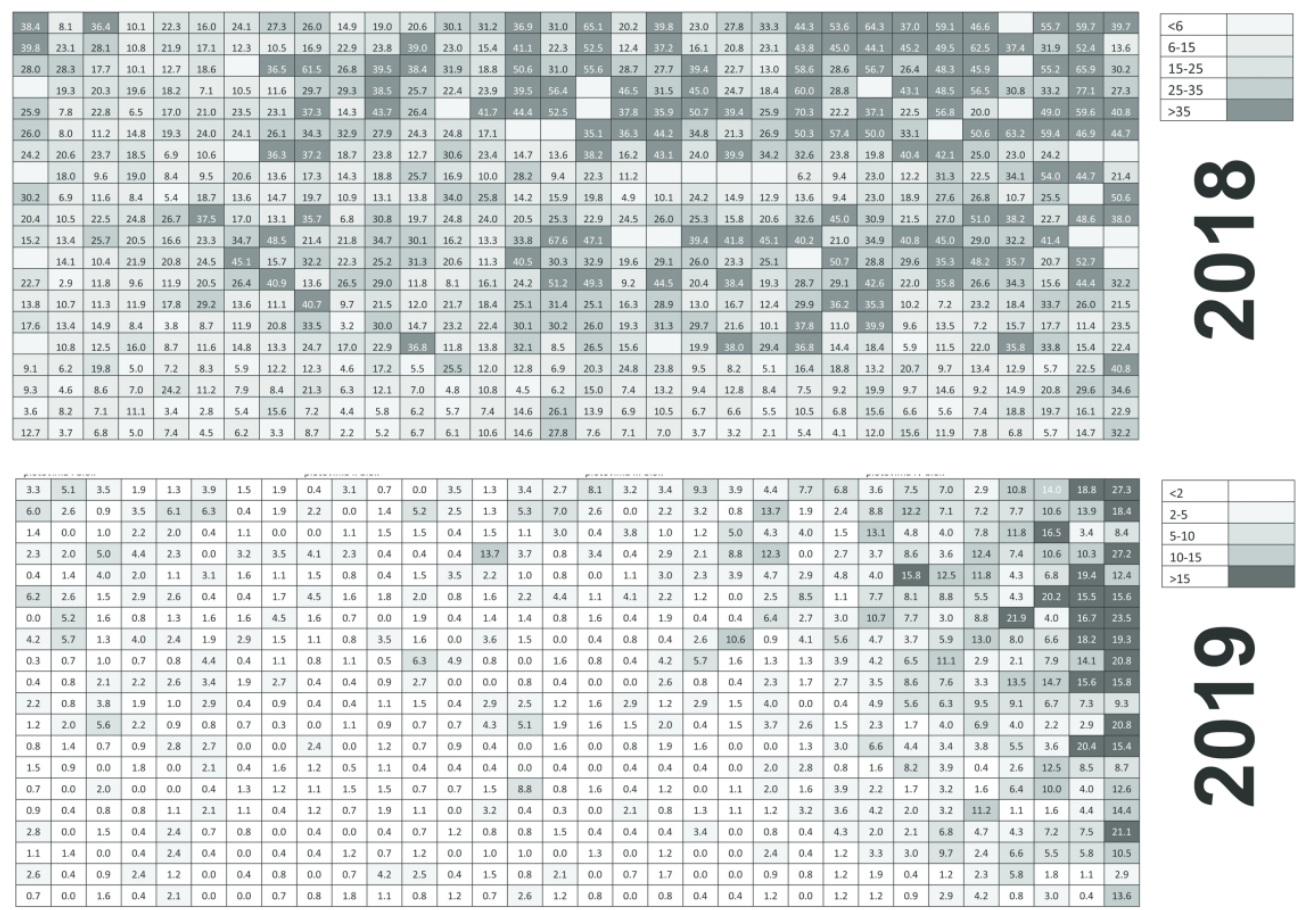

\section{(2) \\ 2 \\ N}

Fig 5. Schematic representation of the map of the experimental field. Each rectangle represents a plot, while numbers and coloured rectangles represent prevalence (in \%) in each plot. Empty rectangles in 2018 represent plots with poor germination, excluded from analyses. 